\title{
Colonic Cancer Arising in Polyposis Coli
}

\author{
DAVID J. B. ASHLEY
}

From Morriston Hospital, Swansea

\section{Available Data}

Polyposis coli is a well-known inheritable disease due to the action of a single autosomal dominant gene. The affected patient has in his colon innumerable small polypoid excrescences from the mucosa and, given sufficient time, one or more of these develops into a malignant epithelial tumour, carcinoma of the colon. Carcinoma of the colon also, indeed much more frequently, occurs in patients who do not have multiple colonic polyps; in such patients the tumour becomes manifest with a frequency which increases rapidly with age. Study of the age specific incidence rates for regions of England and Wales given in the report Cancer in Five Continents (Doll, Payne, and Waterhouse, 1966) shows that the points fit very closely to a straight line on double logarithmic paper and therefore correspond to the expression:

$$
\text { (1) } \mathrm{I}=k t^{r-1} \text {. }
$$

The values of $r-1$ calculated by the method of least squares are: for colonic cancer in males 5.3 and in females 4.4 ; for rectal cancer in males 5.5 and in females 4.3 . The difference in the slopes of the curves in males and females are systematic and significant and are discussed elsewhere in connexion with the differences in tumour incidence in males and females (Ashley, 1969a).

Age-specific incidence curves of this type have been reported by Armitage and Doll (1954) who interpreted them as showing that the process of carcinogenesis involves a number of 'hits', $r$, equal to one more than the exponent in formula 1. A modification of this theory, in which it is suggested that one of the changes may involve an increase in the speed of cell division (Fisher, 1958) reduces the number of 'hits' to $r-1$ or $r-2$, according to whether the increased cell multiplication is in two dimensions or three. Following this theory, the validity of which I have discussed elsewhere (Ashley, 1969b), the number of 'hits' to be postulated in the male is 4 or 5 and in the female 3 or 4 .

Received February 5, 1969.
The frequency with which colonic cancer is seen in patients with polyposis coli also increases as a function of age. I have re-analysed the comprehensive data of Veale (1965) to determine the way in which malignant transformation depends on age in patients suffering from this condition. I extracted from Veale's data the age at which polyposis was treated by removal of the colon and the age at which cancer developed in each case. The Table shows these data for the two sexes separately. In each sex and at each age period the first column shows the number of patients who underwent colonic resection and the second column shows the number of cases of carcinoma which developed. The third column shows the total number of cases of cancer which had developed by the age given and the fourth column shows the total number of patients available for prevalence analysis at that age. This number comprises all the cases of cancer and those patients who underwent resection after that age. It was assumed that colonic resection removed the risk of neoplasia. The final column in each sex gives the prevalence of the tumour to the stated age.

When plotted, the curves for prevalence of cancer in polyposis coli show a steady increase with increasing age up to the age of 35, the slope then decreases and the curve asymptotically approaches $100 \%$. The slopes of the initial parts of the curve for either sex were calculated by the method of least squares. The slope, in the case of males, corresponded to the exponent $4 \cdot 1$, and, in the case of females, to the exponent $3 \cdot 4$.

These exponents, however, refer to prevalence and not to incidence. The two are related quite simply; the prevalence is the sum of the incidences or the integral, from $\mathrm{O}$ to $\mathrm{t}$ of the incidence.

$$
\text { (2) } \mathrm{P}=\int_{0}^{t} k t^{r-1} d t=\frac{k t^{r}}{r} \text {. }
$$

Hence the exponent- $r-$ of the prevalence expression is equal to the number of 'hits' (Armitage and Doll, 1954) or to 2 or 3 more than the number of 'hits' (Fisher, 1958). The slope of the prevalence curve for cancer arising in polyposis coli therefore 
TABLE

AGE DEPENDENCE OF CANCER IN POLYPOSIS COLI (FROM VEALE, 1965)

\begin{tabular}{|c|c|c|c|c|c|}
\hline Age (yr.) & $\begin{array}{c}\text { Cases of } \\
\text { Polyposis } \\
\text { Treated }\end{array}$ & $\begin{array}{l}\text { Cases of } \\
\text { Cancer }\end{array}$ & $\begin{array}{l}\text { Summed } \\
\text { Cases of } \\
\text { Cancer }\end{array}$ & $\begin{array}{c}\begin{array}{c}\text { Total } \\
\text { for } \\
\text { Analysis }\end{array}\end{array}$ & $\begin{array}{c}\text { Prevalence } \\
(\%)\end{array}$ \\
\hline $\begin{array}{c}\text { Male } \\
10 \\
15 \\
20 \\
25 \\
30 \\
35 \\
40 \\
45 \\
50 \\
55 \\
60 \\
65 \\
70 \\
75 \\
\text { Female } \\
10 \\
15 \\
20 \\
25 \\
30 \\
35 \\
40 \\
45 \\
50 \\
55 \\
60 \\
65 \\
70\end{array}$ & $\begin{array}{r}5 \\
7 \\
11 \\
10 \\
14 \\
15 \\
5 \\
9 \\
3 \\
1 \\
1 \\
- \\
2 \\
10 \\
8 \\
14 \\
11 \\
3 \\
6 \\
1 \\
3 \\
2 \\
-\end{array}$ & $\begin{array}{r}1 \\
6 \\
14 \\
17 \\
8 \\
14 \\
6 \\
3 \\
2 \\
1 \\
1 \\
2 \\
1 \\
2 \\
5 \\
8 \\
10 \\
7 \\
6 \\
10 \\
3 \\
1 \\
1\end{array}$ & $\begin{array}{r}1 \\
1 \\
7 \\
21 \\
38 \\
46 \\
60 \\
66 \\
69 \\
71 \\
72 \\
73 \\
75 \\
\\
1 \\
1 \\
3 \\
8 \\
16 \\
26 \\
33 \\
39 \\
49 \\
52 \\
53 \\
53 \\
54\end{array}$ & $\begin{array}{r}156 \\
151 \\
144 \\
133 \\
123 \\
109 \\
94 \\
89 \\
80 \\
77 \\
76 \\
76 \\
75 \\
75 \\
\\
114 \\
112 \\
102 \\
94 \\
80 \\
69 \\
66 \\
60 \\
59 \\
56 \\
56 \\
54 \\
54\end{array}$ & $\begin{array}{c}0 \\
0.66 \\
0.69 \\
5.3 \\
17.0 \\
35.0 \\
49.0 \\
67.0 \\
82.5 \\
89.5 \\
93.0 \\
95 \cdot 0 \\
97.0 \\
100.0 \\
\\
0.88 \\
0.89 \\
2.9 \\
8.5 \\
20.0 \\
38.0 \\
50.0 \\
65.0 \\
83.0 \\
93.0 \\
95.0 \\
98.0 \\
100.0\end{array}$ \\
\hline
\end{tabular}

corresponds to 2 'hits' less than does the slope of the age-specific incidence curves in either sex. This implies that the gene for polyposis coli replaces one or two of the changes customarily essential in the genesis of colonic neoplasms. It is more probable that one change is effected by the gene and that the other apparent hit is, on the basis of Fisher's suggestion, the effect of an increase in cell numbers. The absolute prevalance of cancer in polyposis coli is enormously greater than the prevalence of carcinoma in the general population. If it is assumed that there is no significant loss of susceptible population, which at the levels of incidence considered is reasonable, the prevalence at age $t$ equals the sum of the incidence rates to that age. Starting from the data of Doll et al. (1966), the prevalence at age 50 of colonic cancer in the male population is 1335 per million and in the female population is 1735 per million. In patients carrying the polyposis gene the respective prevalences (Table) are 825,000 and 830,000 per million, which are greater by factors of 620 and 470 . By the age of 70 the prevalence in polyposis patients is almost $100 \%$ while in the general population it has only reached 1 in 1000 -lower by a factor of 1,1000 .

\section{Discussion}

Analysis of the data from two sources but for populations both of which were English shows that the slope of age dependence for the development of colonic cancer is less steep in the case of individuals carrying the gene for polyposis coli than in the general population.

If the 'multi hit' hypothesis of Armitage and Doll (1954) is accepted, the difference in slopes suggests that more 'hits' are required in the case of an individual in the general population before a colonic cancer will develop than is the case in an individual who has, in his genome, the gene for polyposis coli.

An alternative suggestion, that the greater frequency of colonic neoplasms in patients with polyposis coli is due simply to the greater number of colonic epithelial cells which are available for malignant change, would lead to a steeper slope in the case of carriers of the polyposis gene. If the gene led to an increase in the number of epithelial cells which was dependent on time the formula of Armitage and Doll (1954)

$$
\text { (3) } I=\frac{N p_{1}-p_{r} t^{r-1}}{r !} \text {, }
$$

where $N$ represents the number of cells at risk would be replaced by $N_{t}=N_{o} . k t$ so that

$$
I=\frac{N_{o} \cdot k \cdot t \cdot p_{1}-p_{r} t^{r-1}}{r !},
$$

the incidence would depend on a higher power of the age than is the case in the general population, and therefore the slope would be steeper in the case of individuals with polyposis than it is in the general population.

The values of $r-1$ in expression (3) are, for males $5 \cdot 3$ and for females $4 \cdot 4$. The corresponding values in the case of polyposis coli, based on the age and sex specific prevalence which is the integral of the incidence, are 3.1 for males and 2.4 for females. These differences, in each sex almost exactly 2 , suggest that 2 more 'hits' are required in the case of the normal individual than in the case of the individual with polyposis. If, in addition, a time-dependent factor for the total number of colonic cells is accepted-expression (4)-it can be postulated that the polyposis gene can replace 3 of the 'hits' necessary for the development of colonic tumours.

If, however, the suggestion of Fisher (1958) is accepted the polyposis gene may replace one 'hit' which results in a change in the cells which carries with it an increased tendency to multiply. The abnormal colon which contains the multiple polyps does, however, need one or more changes, presumably environmental in nature, before colonic cancer develops, so that colonic carcinoma in a patient with polyposis may be regarded as prezygotic cancer (Burch, 1965). 
This hypothesis is supported by the frequent occurrence of a small number of polyps in colons which are the site of cancer, $17 \%$ in my own series of 126 examples of resectable colonic cancer, and by the occurrence of histologically identifiable premalignant changes in polyps of the colon, the adenoma malignum (Lockhart-Mummery and Dukes, 1952) in which invasion has not yet occurred.

Polyposis coli is a relatively common genetically determined congenital anomaly in which it has been possible to assemble enough data for this type of analysis to be performed. It would be interesting if similar surveys in other tumours which are genetically determined could be carried out.

\section{Summary}

Data on the age-specific incidence of colonic carcinoma are compared with data on the agespecific prevalence of colonic cancer in individuals who carry the gene for polyposis coli.

It is shown that the development of colonic cancer can be ascribed to the action of a series of 'hits' on cells of the intestinal mucosa, and that the number of 'hits' necessary for the development of cancer in an individual who carries the gene for polyposis coli is 1 or 2 less than this.
It is suggested that the effect of the polyposis gene is to reduce the number of changes necessary in the intestinal mucosal cells before neoplasia can develop but that the development of cancer in these polyps is dependent on external factors of the same type as in the case of colonic cancer which is not preceded by polyposis.

This work was assisted by a research grant from the Welsh Hospital Board.

\section{REFERENCES}

Armitage, P., and Doll, R. (1954). The age distribution of cancer and a multi-stage theory of carcinogenesis. Brit. F. Cancer, 8, 1.

Ashley, D. J. B. (1969a). A systematic sex difference in intestinal carcinoma. Cancer (Philadelphia). In the press.

- (1969b). The two "hit" and multiple "hit" theories of carcinogenesis. Brit. F. Cancer, $23,313$.

Burch, P. R. J. (1965). Natural and radiation carcinogenesis in man. II Natural leukaemogenesis: initiation. Proc. roy. Soc. B, 162, 240.

Doll, R., Payne, P., and Waterhouse, J. (1966). Cancer Incidence in Five Continents. Union Internationale Contre le Cancer. Springer, Berlin.

Fisher, J. C. (1958). Multiple mutation theory of carcinogenesis. Nature (Lond.), 181, 651.

Lockhart-Mummery, H. E., and Dukes, C. E. (1952). The surgical treatment of malignant rectal polyps. Lancet, 2, 751.

Veale, A. M. O. (1965). Intestinal Polyposis. Eugenics Laboratory Memoirs, No. 40. Cambridge University Press, Cambridge. 